\title{
7 Excellence in Indigenous education
}

\author{
Marnee Shay and Jodie Miller
}

\section{How to use this policy}

Excellence in Indigenous education uses a strengths-based approach to implementing broader Indigenous education policy imperatives. This policy incorporates the goals of a broad range of current Indigenous education policies into an applied way of addressing school-based issues associated with persisting Indigenous education disparities. This new policy will reframe much of the broader policy impetus into school-based approaches to Indigenous education informed by concepts of excellence, strength and aspiration that centres the voices and leadership of Indigenous peoples. Underpinned by Indigenous Research Theory (Rigney, 2006), Critical Race Theory (Ladson Billings, 2005) and Postcolonial Theory (Gandhi, 2019), the policy takes an evidence-based approach to Indigenous policy reform and will provide schools with a streamlined approach to doing Indigenous education that is orientated to Indigenous agency, partnerships and reciprocity. By using the process of co-design (Australian Government, 2020), schools will be able to provide spaces for meaningful community and school partnerships and collaborations to transpire. School leaders and staff will be provided with a framework to work in collaboration with Indigenous students, their families and communities to co-design and localise programs to address education goals that are aimed at enhancing the learning of all students in Australian classrooms.

\section{[INSERT name of school] Excellence in Indigenous education}

\section{Rationale}

The field of Aboriginal and Torres Strait Islander education is saturated with literature that reinforces a bleak outlook in relation to educational outcomes for Indigenous peoples. Amongst the most researched peoples on the planet, there continues to be an abundance of research taking place on the "subject" of Indigenous peoples (Tuhiwai Smith, 2012). Much of this research continues to be undertaken by predominantly non-Indigenous researchers and without 
significant data that privileges the voices and lived experiences of Indigenous peoples (Shay, 2016).

Although there is an abundance of research in the field of Indigenous education, the topic of Indigenous education can be interdisciplinary and complex to research. A synthesis of the literature that focuses on Indigenous learners in schools revealed six key themes where research is focused: identity, cultural capability of educators, engaging with Indigenous families and communities, presence of Indigenous cultures in schools and employment of Indigenous peoples in schools and leadership (Shay \& Heck, 2015). In addition, there has been a sustained focus in the literature on embedding Indigenous knowledges and perspectives into curriculum (Phillips \& Lampert, 2012; Sarra, 2011) as well as the need to enhance the wellbeing of Indigenous learners in schools (Kickett-Tucker, 2009).

In 2017 the Organisation for Economic Cooperation and Development (OECD) published an international study that included Canada, New Zealand and Australia and that investigated promising practices in seeding success for Indigenous students (OECD, 2017). The aim of the study was to identify promising policies and practices that resulted in success for Indigenous students in these three countries and build an evidence base to assist in better policy development and outcomes for Indigenous young people. Despite the existing deficit discourse reinforcing gaps, failures and the problematizing of Indigenous students, the OECD reported that there were many promising practices evident across all three countries, all underpinned by discourses of excellence and success. Moreover, they also reported that not only were these practices of benefit to Indigenous young people, they also benefit nonIndigenous young people by providing a more safe and inclusive schooling environment.

Research in Indigenous education is heavily influenced by political discourse. A focus in policy over the past decade has been on the Close the Gap agenda, which is a quantitative, data-driven policy approach that highlights gaps between Indigenous and non-Indigenous young people in literacy, numeracy, attainment and attendance school outcomes (Australian Government, 2018). This has resulted in deficit discourses influencing policy development and practice (Hogarth, 2018). In response to ongoing calls for Indigenous people to be included in policy development in order to counter these deficit discourses, in 2019 the Australian Government introduced a codesign approach as the new way forward in policy development and implementation in any policy area that affects Indigenous peoples (Australian Government, 2020).

Current national key policy responses to improving Indigenous outcomes include professional standards for teachers and school leaders such as strategies for teaching Aboriginal and Torres Strait Islander students (APST 1.4), which need to be supported by school leaders through developing teaching programs that support equitable and ongoing participation of Aboriginal and Torres Strait Islander students (Australian Institute for Teaching and School 
Leadership [AITSL], 2018). Leaders need to engage in collaborative relationships with community representatives and parents/carers to support and develop these teaching programs (AITSL, 2018). A second professional standard indicates that teachers and leaders need to understand and respect Aboriginal and Torres Strait Islander people to promote reconciliation between Indigenous and non-Indigenous Australians (AITSL, 2018). Furthermore, the embedding of Indigenous knowledges and perspectives in the national curriculum has also been identified as a cross-curriculum priority area by the Australian Curriculum, Assessment and Reporting Authority (Australian Curriculum, Assessment and Reporting Authority [ACARA], 2018).

\section{Purpose}

The purpose of this policy is to outline the shared responsibility of education for Aboriginal and Torres Strait Islander peoples for the whole school community, inclusive of parents and community, students, staff, teachers and school leadership. It emphasises the importance of co-design and strengthsbased approaches building on evidence-based practices. Every Aboriginal and Torres Strait Islander student has the right to experience excellent teaching and learning practices that affirm their culture and identity. Every student in Australian classrooms has the right to learn about Australian histories and Indigenous peoples, cultures and languages. The policy provides practical steps for current policy imperatives in Indigenous education underpinned by the concept of excellence.

\section{Scope}

This policy applies to students, teachers, staff, school leaders and parents and community members of [INSERT name of school]. A strengths-based approach to excellence in Indigenous education is overseen by all members of the school community with an emphasis on partnership and co-design. The policy emphasises a way of implementing existing Indigenous education goals that emphasises strengths, agency, partnership and co-design.

\section{Policy statement}

\section{School management}

At [INSERT name of school] we affirm Aboriginal peoples and Torres Strait Islander peoples are the First Australians and have the oldest living cultures in human history. We also acknowledge that Aboriginal peoples and Torres Strait Islander peoples have strong cultural traditions and speak diverse languages and dialects, other than Standard Australian English. 
To ensure the wellbeing of all members of our school community, [INSERT name of school] has a range of strategies to actively address the issue of racism (Bodkin-Andrews et al., 2013).

[INSERT name of school] ensures all school staff undertake regular cultural capability training that includes local knowledges and knowledge holders (i.e., Elders) (Gorringe \& Spillman 2009). Where possible, this training should link closely to the community in which the school is located.

Leadership at [INSERT name of school] has specific strategies to engage in active and genuine partnerships with local Indigenous families and communities, providing meaningful opportunities for input into all aspects of education involving their children (Lowe et al, 2019).

[INSERT name of school] values Indigenous knowledges and proactively ensures their presence through display of flags and the map of Indigenous Australia; use of local languages on signage; and inclusion of cultural spaces, such as yarning circles (Davis \& Grose, 2008).

[INSERT name of school] is committed to ensuring the employment of Indigenous leaders, teachers and support staff at the equivalent percentage of the Indigenous student population (Santoro \& Reid, 2006).

[INSERT name of school] creates a culture of high expectation relationships, with an emphasis on teacher-student relationships (Sarra et al., 2018).

[INSERT name of school] provides Indigenous students with a range of opportunities to excel, including in academic disciplines, cultural activities and the arts (Shay \& Miller, 2019).

As a key priority, [INSERT name of school] will implement Indigenous knowledges and perspectives across all curriculum areas (ACARA, 2020). This will be led in conjunction with community members and parents to localise the perspectives embedded in the curriculum.

Programs implemented at [INSERT name of school] will be endorsed by Aboriginal and Torres Strait Islander community representatives, and [INSERT name of school] will ensure that they meet the needs, priorities and aspirations of their communities (Australian Government, 2020). In addition to this, ongoing evidence and accountability measures will be collected to ensure that the program is continuing to improve and support excellent education practices for the school community.

The leadership team at [INSERT name of school] will act on parent, student and community suggestions and feedback (Povey et al., 2016).

\section{Teachers}

Teachers at [INSERT name of school] have specific principles and practice to support and affirm the identities of Aboriginal and Torres Strait Islander students (Shay, Sarra \& Woods, 2020).

Teachers at [INSERT name of school] seek to have positive relationships with Indigenous students, their families and communities (Buckskin, 2012). 
Teachers at [INSERT name of school] have the skills and confidence to embed Aboriginal and Torres Strait Islander perspectives and knowledges across all curriculum areas. They will co-construct curriculum with community members, parents and students (Armour \& Miller, 2020).

Teachers at [INSERT name of school] draw on evidence-based practices to support a strengths-based approach to teaching, learning and assessment that is culturally responsive and provides the opportunities for students to excel (Miller \& Armour, 2019).

Teachers at [INSERT name of school] ensure all students are presented with a range of Indigenous role models across all fields and professions (Shay, Sarra \& Woods, 2020).

Teachers at [INSERT name of school] embed critical self-reflection as a regular professional practice (Phillips \& Lampert, 2012).

\section{Students}

All students at [INSERT name of school] will engage respectfully with learning about Indigenous and Australian cultures, histories and peoples.

At [INSERT name of school] all students are encouraged and will be given the opportunity to use their personal strengths in their learning. Teachers will adapt learning experiences to link closely with students' local contexts to provide these opportunities (Armour \& Miller, 2020).

Students at [INSERT name of school] from all cultural backgrounds will contribute positively to creating a sense of belonging for all students in their school community.

\section{Parents}

[INSERT name of school] is a school that is culturally welcoming and promotes agency for parents. It values and welcomes all parents, guardians and family members into the community.

Parents of [INSERT name of school] are empowered to support their child's learning and engage meaningfully in school life.

[INSERT name of school] engages with positive communication with parents and works with community leaders and agencies to foster two-way communication (or multiple communication channels) with families (Povey et al., 2016).

[INSERT name of school] will form respectful and collaborative partnerships with parents (the agents for their child) to seek feedback and overall satisfaction with school and communication from the school (Reschley et al., 2008).

Educational opportunities for parents are provided throughout the year at [INSERT name of school] that directly link to programs that support their child's learning. These opportunities enhance connectedness with the school and other parents (Povey et al., 2016). 


\section{Rating of evidence base}

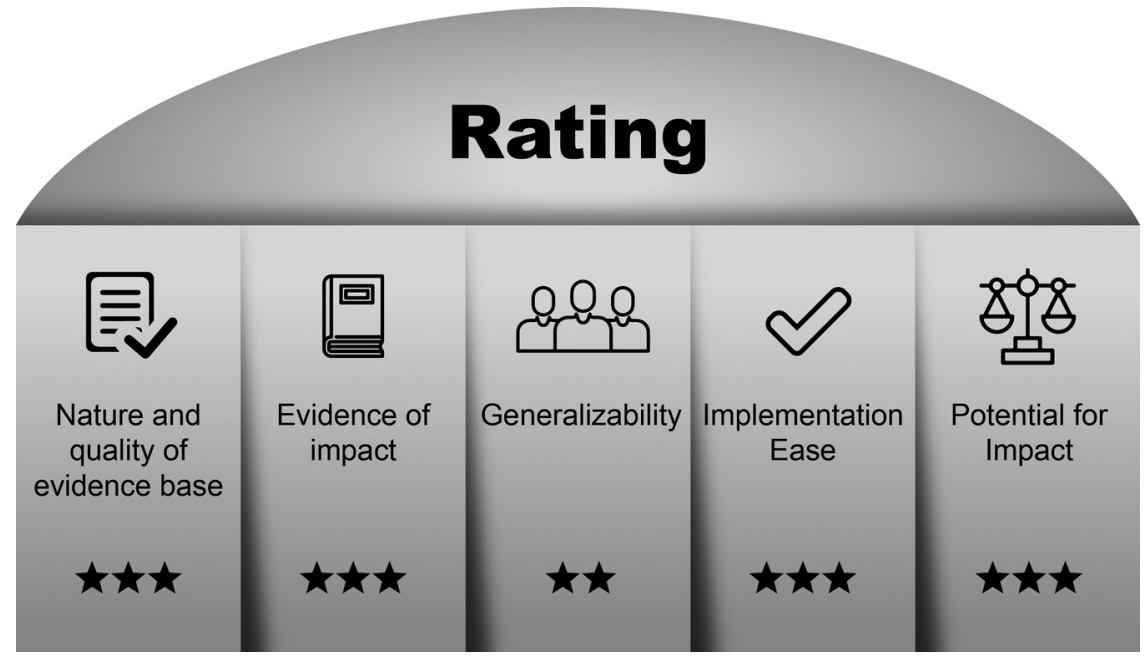

Figure 7.1. Excellence in Indigenous Education Rating of Evidence.

Author Note. There are complexities in rating the existing evidence in the field of Indigenous education. Indigenous peoples have been excluded from knowledge production and have been subject to racialised constructs produced by what is termed the "colonial gaze". Whilst there is a growing number of Indigenous scholars, the vast majority of knowledges produced in the field of Indigenous education have been produced by non-Indigenous scholars. This has resulted in bias within the realm of what is considered evidence.

\section{Authorship}

Dr Marnee Shay, The University of Queensland

Dr Jodie Miller, The University of Queensland

[INSERT RELEVANT STAFF MEMBERS]

\section{Related policy and documents}

\section{[INSERT RELEVANT POLICY AND DOCUMENTS]}

Building better schools through visible and transparent practice

School belonging

Student wellbeing interventions

Teacher wellbeing

Using research evidence to inform classroom practices

Inclusivity and equity in the classrooms through student voice and agency

Using research evidence to drive school improvement

School-community collaboration policy

Supporting transitions 


\section{Date of ratification}

This policy was ratified on the [INSERT DATE].

\section{Date of review}

This policy will be reviewed by [INSERT DATE].

\section{Further reading}

United Nations for Indigenous Peoples: Recommendation on education https:// www.un.org/development/desa/indigenouspeoples/mandated-areas1/educa tion/recs- education.html

United Nations for Indigenous Peoples: Education https://www.un.org/devel opment/desa/indigenouspeoples/mandated-areas1/education.html

\section{Expert consultation}

To enact this policy, school leaders will need to consult with Aboriginal and Torres Strait Islander people in their local community. Indigenous peoples from the communities in which the school is situated are important and valuable knowledge holders and to successfully implement this policy, schools must work in partnership with diverse members of these communities.

\section{References}

Armour, D. \& Miller J. (2020). Relational pedagogies and co-constructing curriculum with students. In M. Shay \& R. Oliver (Eds). Learning and teaching for deadly futures. Routledge.

Australian Curriculum, Assessment and Reporting Authority [ACARA]. (2020). Aboriginal and Torres Strait Islander histories and cultures. https://www.australiancurriculum. edu.au/f-10-curriculum/cross-curriculum-priorities/aboriginal-and-torres-strait-islanderhistories-and-cultures/

Australian Government. (2018). Close the cap: Prime Minister's report 2018. https:// closingthegap.pmc.gov.au/sites/default/files/ctg-report-2018.pdf?a=1

Australian Government. (2020). Indigenous voice. National Indigenous Australians Agency. https://www.niaa.gov.au/indigenous-affairs/indigenous-voice

Australian Institute for Teaching and School Leadership [AITSL]. (2018). Australian professional standards for teachers. https://www.aitsl.edu.au/teach/standards

Bodkin-Andrews, G. H., Denson, N., \& Bansel, P. (2013). Teacher racism, academic self-concept, and multiculturation: Investigating adaptive and maladaptive relations with academic disengagement and self-sabotage for Indigenous and non-Indigenous Australian students. Australian Psychologist, 48(3), 226-237.

Buckskin, P. (2012). Engaging Indigenous students: The important relationship between Aboriginal and Torres Strait Islander students and their teachers. In K. Price (Ed.), Aboriginal and Torres Strait Islander education: An introduction for the teaching profession (pp. 165-180). Cambridge University Press. 
Davis, J., \& Grose, S. (2008). Which Way? What Happens when embedding Aboriginal and Torres Strait Islander perspectives in schools meets the professional standards for teachers and accountability matrix?Indigenous Education Leadership Institute. https:// strongersmarter.com.au/wp-content/uploads/2013/01/Which_Way_by_John_Davis_ and_Sharon_Grose_for_Wipce_2008.pdf

Gandhi, L. (2019). Postcolonial theory: A critical introduction. Columbia University Press.

Gorringe, S. D., \& Spillman, D. (2009). Creating stronger smarter learning communities: The role of culturally competent leadership. Queensland University of Technology.

Hogarth, M. (2018). Talkin' bout a revolution: the call for transformation and reform in Indigenous education. The Australian Educational Researcher, 45(5), 663-674.

Kickett-Tucker, C. S. (2009). Moorn (Black)? Djardak (White)? How come I don't fit in Mum? Exploring the racial identity of Australian Aboriginal children and youth. Health Sociology Review: Social Determinants of Child Health and Well-Being, 18(1), 119-136.

Ladson-Billings, G. (2005). The evolving role of critical race theory in educational scholarship. Race Ethnicity and Education, 8(1), 115-119.

Lowe, K., Harrison, N., Tennent, C., Guenther, J., Vass, G., \& Moodie, N. (2019). Factors affecting the development of school and Indigenous community engagement: A systematic review. The Australian Educational Researcher, 46(2), 253-271.

Miller, J., \& Armour, D. (2019). Supporting successful outcomes in mathematics for Aboriginal and Torres Strait Islander students: a systematic review. Asia-Pacific Journal of Teacher Education, 1-17.

Organisation for Economic Cooperation and Development [OECD]. (2017). Promising practices in supporting success for Indigenous students. OECD Publishing. doi:10.1787/ 9789264279421-en

Phillips, J., \& Lampert, J. (2012). Introductory Indigenous studies in education (2nd ed.). Pearson.

Povey, J., Campbell, A. K., Willis, L. D., Haynes, M., Western, M., Bennett, S., ... \& Pedde, C. (2016). Engaging parents in schools and building parent-school partnerships: The role of school and parent organisation leadership. International Journal of Educational Research, 79, 128-141.

Reschly, A. L., Huebner, E. S., Appleton, J. J., \& Antaramian, S. (2008). Engagement as flourishing: The contribution of positive emotions and coping to adolescents' engagement at school and with learning. Psychology in the Schools, 45(5), 419-431.

Rigney, L. (2006). Indigenist research and Aboriginal Australia. In N. Goduka \& J. Kunnie (Eds.), Indigenous people's wisdoms and power: Affirming our knowledges through narrative (pp. 32-50). Ashgate Publishing.

Santoro, N., \& Reid, J. A. (2006). "All things to all people": Indigenous teachers in the Australian teaching profession. European Journal of Teacher Education, 29(3), 287-303.

Sarra, C., Jackson, D., Davis, J., Spillman, D., \& Bray, J. (2018). High-expectations relationships: A foundation for enacting high expectations in all Australian schools. Australian Journal of Indigenous Education, 1-14.

Sarra, G. (2011). Indigenous studies in all schools. International Journal of Inclusive Education, 15(6), 611-625. 


\section{Shay \& Miller}

Shay, M. (2016). Seeking new paradigms in Aboriginal education research: Methodological opportunities, challenges and aspirations. Social and Education History, 5(3), 273-296.

Shay, M., \& Heck, D. (2015). Alternative education engaging Indigenous young people: Flexi schooling in Queensland. The Australian Journal of Indigenous Education, 44(1), 37-47.

Shay, M. \& Miller, J. (2019). Doing things right way: dimensions of excellence in Indigenous education in Queensland secondary schools. Australian Association for Research in Education, Brisbane, Australia, 1-5 December.

Shay, M., Sarra, G. \& Woods, A. (2020) Strong identities, strong futures: Indigenous identities and wellbeing in schools. In M. Shay \& R. Oliver (Eds). Learning and teaching for deadly futures. Routledge.

Tuhiwai Smith, L. (2012). Decolonizing methodologies: Research and Indigenous peoples (2 ed.). Zed Books. 